\title{
Yargıya yansıyan omuz cerrahisi uygulanmış olguların tıbbi ve hukuki değerlendirilmesi
}

\author{
Medical and legal evaluation of cases reflected in the judgment of \\ shoulder surgery
}

\author{
Serdar Şirazi ${ }^{1}$, İrfan Esenkaya ${ }^{2 \star}$, İlhan Açıkgöz ${ }^{3}$ \\ ${ }^{1}$ Ortopedi ve Travmatoloji Uzmanı, Hukukçu, Arabulucu, Özel Avcılar Anadolu Hastanesi, Şahin Avukatlık Bürosu, \\ Akademi Arabuluculuk ve Tahkim Merkezi, İstanbul \\ ²Emekli Öğretim Üyesi, Ortopedi ve Travmatoloji Uzmanı, SANTE Tıp Merkezi, İstanbul \\ *Tıp Hukuku Yüksek Lisansı, MA \\ ${ }^{3}$ Ortopedi ve Travmatoloji Uzmanı, Hastane ve Sağlık İşletmeleri Yöneticisi, Doktor Avukat, Sağlık Hukuku Uzmanı, \\ İstanbul Barosu Avukatı
}

\begin{abstract}
Teknolojik gelişmelere paralel olarak açık yapılabilecek birçok cerrahi girişim artroskopik olarak başarılı bir şekilde yapılabilmektedir. Omuz artroskopisinden sonra ortaya çıkabilecek komplikasyonlar bir yana, Sosyal Güvenlik Kurumu'nun geri ödeme veya özel sağlık sigortasının yapılan cerrahi müdahaleyi karşılama yöntemlerinden kaynaklanan oldukça sık uyuşmazlıklar bulunmaktadır. Makalemizde omuz bölgesi kırıklarına yönelik uygulamalar kapsam dışı tutulmuştur. Omuz cerrahisine yönelik artroskopi uygulamaları, Sosyal Güvenlik Kurumu ve özel sağlık sigortası geri ödemelerine yönelik ortaya çıkan davalara yer verilerek ana hatları ile durumun hukuksal boyutu ve gelecekte bu konuda ortopedi ve travmatoloji uzmanın bekleyen olası riskler konusunda tespitlerde bulunmak hedeflenmiştir.
\end{abstract}

Anahtar sözcükler: artroskopi; omuz; sağlık hukuku; tıp hukuku
In parallel with technological developments, many surgical interventions, that can be performed openly, can also be successfully performed arthroscopically. Apart from the complications that may arise after shoulder arthroscopy, there are quite frequent conflicts arising from the reimbursement of the Social Security Institution and the coverage of the surgical intervention by the private health insurance. In our article, applications for shoulder fractures are excluded. It is aimed to determine the legal dimension of the situation and the possible risks awaiting the orthopedics and traumatology specialist in the future, by presenting arthroscopy applications for shoulder surgery, the cases related to the Social Security Institution and private health insurance reimbursement.

Key words: arthroscopy; shoulder; health law; medical law

omuz artroskopisi ile ilgili özel sağlık sigortasından kaynaklanan bir uyuşmazlık da makalede yer almaktadır.

\section{ÖRNEK OLGU 1}

İdareye karşı açılan örnek dava, Sağlık Bakanlığı Tedavi Hizmetleri Genel Müdürlüğü tarafından 06.07.2009 tarihinde 2009/42 sayılı Genelgesini konu almaktadır. ${ }^{[1]}$ Genelgenin Ek-1'indeki "Cerrahi Müdahale Birimlerinde Uygulanacak Cerrahi Müdahale Listesi"nde ameliyatların puanı ve grubu belirtilmiştir. Ancak Kemik ve Eklem Hastalıkları Cerrahisi ana başlıyönelik ortaya çıkan davalara yer verilmiştir. Ayrıca

iletişim / Contact: Dr. Serdar Şirazi • E-posta / E-mail: drserdarsirazi@yahoo.com

ORCID iD: Serdar Şirazi, 0000-0002-2155-1894 • İrfan Esenkaya, 0000-0002-7321-0012 • İlhan Açıkgöz, 0000-0002-5511-0341

Geliş / Received: 18 Ocak 2021 • Kabul / Accepted: 14 Şubat 2021 
ğında Artroskopi başlığında sadece tanısal artroskopinin puanı ve grubu belirtilmiş, omuz artoskopisinin puanı ve grubuna yer verilmemiştir. Söz konusu genelgede Kemik ve Eklem Hastalıkları Cerrahisi bölümünde tedavi edici-girişimsel artroskopiye yer verilmeyerek eksik düzenleme nedeniyle genelgenin iptali davası açılmıştır.

Danıştay Onbeşinci Hukuk Dairesi'nce ${ }^{[2]}$, genelgenin ${ }^{[1]}$ iptalini gerektiren bir husus bulunmadığı gerekçesiyle, dava konusu genelgenin iptali isteminin reddine; Cerrahi Müdahale Birimlerinde Uygulanacak Cerrahi Müdahale Listesi konulu Genelgenin eki Ek-1 "Cerrahi Müdahale Birimlerinde Uygulanacak Cerrahi Müdahale Listesi"nin daha önce, Cerrahi Müdahale Uygulanacak Sağlık Kuruluşlarında Tıp Dallarına Göre Uygulanabilecek Cerrahi Müdahaleler Listesi'nin ortopedi bölümünde artroskopik cerrahi girişimlerin yer aldığını, ancak dava konusu genelgenin ekindeki listede sadece tanısal amaçlı artroskopiye yer verildiğinin görüldüğünü, artroskopik cerrahi girişimlerin dava konusu genelge eki Cerrahi Müdahaleler Listesi'nden çıkarılmasına ilişkin olarak davalı idare tarafından bilimsel herhangi bir gerekçe ortaya konulamadığını belirtmiştir. Bu açıklamaya binaen dava konusu Genelgenin eki Ek-1 "Cerrahi Müdahale Birimlerinde Uygulanacak Cerrahi Müdahale Listesi”nin Kemik ve Eklem Hastalıkları Cerrahisi bölümünde, tedavi edici-girişimsel artroskopiye yer verilmemesi şeklindeki eksik düzenlemede hukuka uyarlık görülmediği gerekçesiyle iptaline karar verilmiştir.

Davacı taraf sadece Ek-1'de bulunan listenin iptalinin değil genelgenin tamamının iptali istemiyle temyiz edilmesi üzerine, İdari Dava Daireleri Kurulu'nun kararı ile genelgenin tamamının iptaline oy birliğiyle karar verilmiştir.

\section{ÖRNEK OLGU 2}

Örnek dava, daha sonra iptal edilen genelgeye ${ }^{[1]}$ bağlı ortaya çıkan uyuşmazlık ile ilgilidir. Genelgenin yayınlandığı tarih olan 06.07.2009 ile ekinin iptal edildiği, 25.03.2010 arasında yapılan tedavi edici omuz artroskopisi işlemlerinin puanı ve grubu bulunmaması nedeniyle Sosyal Güvenlik Kurumu sağlık kuruluşlarına herhangi bir geri ödemede bulunmamıştır. Bu iki tarih arasında yapılan bir ameliyatın kurum tarafından ödenmemesi üzerine açılan davada, kurum sağlık merkezinde yapılan girişimsel artroskopi işleminin 2009/42 sayılı Genelgede ${ }^{[1]}$ bulunmadığı gerekçesiyle 114.138,60 TL kesinti uygulamış, hastane idaresi tarafından kesinti tarihi itibarıyla uygulanacak yasal faizi ile birlikte Sosyal Güvenlik Kurumu'ndan tahsiline karar verilmesini istemiştir.

Mahkemece, 07.07.2009-25.03.2010 tarihleri arasında yürürlükte bulunan Sağlık Bakanlığı'nın 2009/42 sayılı Genelgesi[ ${ }^{[1]}$ kapsamında davacı kuruluşun sadece tanısal artroskopi hizmeti verebileceği girişimsel artroskopi işlemleri yapma yetkisi bulunmadığını, davacıya uygulanan cezai işlemin yerinde olduğunu, Genelgenin sonradan yürürlükten kaldırılmasının yapılan işlemlere geçerlilik sağlamayacağını, tıbbi risk taşıyan operasyonlara ilişkin kurallara sıkı sıkıya şeklen de olsa bağlılık şartı olduğu gerekçesiyle davanın reddine karar vermiştir.

Davacı hastane vekili tarafından karara itiraz edilmiş ve Yargıtay Onüçüncü Hukuk Dairesi 26.09.2018 tarihli kararında ${ }^{[3]}$ 10.03.2010 tarihinde yapılan yönetmelik değişikliği ile Ek-9 adıyla "Tıp Merkezlerinde Gerçekleştirilebilecek Cerrahi Müdahale Listesi” yayımlandığı, bu listede tanısal artroskopi ve girişimsel artroskopinin yer aldığını, davayı reddeden mahkemenin lehe olan yönetmelik değişikliği uyarınca bir karar verilmesi gerekirken yanılgılı gerekçe ile yazılı şekilde davanın reddine karar verilmesinin usul ve yasaya aykırı olduğu gerekçesiyle davacı hastane lehine yerel mahkeme kararını bozmuştur.

Yorum: Söz konusu genelgenin iptali ile omuz artroskopisi yapılacak müdahalelerin kurum tarafından geri ödemesinde ortaya çıkabilecek problemler giderilmiş olmakla birlikte genelgenin ${ }^{[1]}$ yürürlükte olduğu dönemde meydana gelen ödeme uyuşmazlıklarında da lehe karar verilerek sağlık kuruluşlarına uygulanan kesintiler de iptal edilmiştir.

Ayakta Teşhis ve Tedavi Yapılan Özel Sağlık Kuruluşları Hakkında Yönetmelikte Değişiklik Yapılmasına Dair Yönetmeliğin, Ek-9, Artroskopiler bölümünde de (Sıra; 665-86) değişiklikler yapıldığından ${ }^{[4]}$; 2009/42 sayılı Genelge, 25.03.2010 tarih ve 12622 sayılı Makam Onayı ile yürürlükten kaldırılmıştır. ${ }^{[5]}$

\section{ÖRNEK OLGU 3}

Omuz artroskopisi ile ilgili bir diğer karar örneğinde davacı hastane sigortalının SLAP (superior labral anterior posterior) onarımı ve artroskopik akromiyoplasti ameliyatı olan hastanın Sosyal Güvenlik Kurumu'nun ödeme yapmamasını konu almaktadır. Yerel mahkemenin, kurumu haklı görerek kesintiyi uygun bulmuş olması üzerine istinaf başvurusunda bulunulmuş. Kurum, yapılan savunmasında hastanın çekilen omuz manyetik rezonans (MR) raporunda "glenoid labrum normaldir" denilmesine rağmen artroskopik SLAP onarımı yapılmasından dolayı kesinti yapıldığını belirtmiş. ${ }^{[6]}$

Yargıtay Onüçüncü Hukuk Dairesi[i] kararında dosyada bulunan, ortopedi ve travmatoloji uzmanı bilirkişiden alınan raporda; SLAP lezyonlarının tanısının artroskopik olarak konulduğunu, MR görüntülemenin labral patolo- 
jileri göstermede yeterli olmayabileceği, kesin tanının artroskopi ile konulduğu bildirilmiş ve hastaya yapılan operasyon sırasında SLAP lezyonunun varlığı gözlenerek onarılması işleminin tıbba uygun olduğu kanaatine varıldığı belirtilmiş. Yine aynı raporda hastanın MR sonucunda biseps ankoru altında sıvı varlığının gözlemlendiği, bunun da SLAP lezyonunun varlığını desteklediği ayrıca belirtilmiş. Buna göre SLAP lezyonunun MR'de görülememiş olmasının mevcut olmadığı anlamına gelmediği, SLAP lezyonlarının genellikle MR'de teşhis edilemeyip artroskopi sırasında tespit edildiği belirtilmiş. Yargıtay bu nedenle somut olayda operasyon sırasında tespit edilerek onarılmasının tıp bilimine ve Sağlık Uygulama Tebliği (SUT) hükümlerine uygun olduğunu, hastanın MR sonucunda lezyonun varlığını desteklediği göz önünde bulundurulduğunda davalı kurumun yaptığı kesintinin hukuka uygun olmadığına ve ilk derece mahkemesi kararının bozulmasına karar vermiştir. ${ }^{[6]}$

Yorum: Dosyada mahkemenin değerlendirmeye tabi tuttuğu bilirkişi raporu uyuşmazlığın çözümünde oldukça etkili olmuştur. Superior labral anterior posterior lezyonlarının tanısının sadece MR görüntüsüyle konulmayacağı, artroskopi ile de lezyonların varlığının belirtilebileceği önem arz etmektedir. Bu gibi durumlarda artroskopi görüntüsünün saklanması olası uyuşmazlıkların çözümünde oldukça değerli belge özelliğine haiz olacaktır.

\section{ÖRNEK OLGU 4}

Davacı omuz ağrısı şikâyetiyle özel bir hastaneye başvurmuş, ortopedi ve travmatoloji hekimi tarafından omuz MR tetkiki istenmiş. Ortopedi ve travmatoloji hekimi tarafından MR raporunda sıkışma (impingement) tespit edilerek hastaya fizik tedavi önerilmiş. Şikâyetleri devam eden hasta yaklaşık iki ay sonra aynı merkeze başvurmuş ve impingement tanısıyla ortopedi ve travmatoloji uzmanı tarafından ameliyat edilmiş. Hastaya daha sonra tekrar MR çekilmesi üzerine lenfoma tanısı konulmuş. Bunun üzerine hasta geriye dönük yapılan inceleme sonucunda tümörün ilk çekilen omuz MR tetkikinde de bulunduğunu, ancak radyolog tarafından rapor edilmediğini, kendisine yapılan impingement ameliyatının ilgisiz ve gereksiz olduğu ve kanser tedavisinde erken teşhisin öneminin olduğunu belirterek dava açmış. ${ }^{[7]}$

09.04.2012 tarihli Adli Tıp Kurumu raporunda belirtilen gelişmekte olan lenfomanın onkolojik radyoloji ile uğraşmayan radyologlarca ön tanıya bağlı olarak yorumlanamayabileceği, 12.07.2010 tarihli sağ omuz MR'de oluşan değişikliklerin radyolog tarafından malignite lehine değerlendirildiği ve biyopsi önerildiği, ortopedi ve travmatoloji uzmanı tarafından klinik bulgu 17.04.2010 tarihli sağ omuz MR'ye göre değerlendirdiği ve omuz artroskopisini yaptığı, 17.04.2010 tarihli sağ omuz MR`de lenfoma tanısının konulmamasının bir eksiklik olsa da lenfoma tanısına yol açan patolojik değişikliklerin aynı radyoloji uzmanı tarafından üç ay sonra konulmasının prognozu kötü yönde etkileneceğinin tıbben ispat edilemeyeceği gibi kişide ek bir zarar oluşturmadığının tespit edildiğinden dolayı radyoloji uzmanı ile ortopedi ve travmatoloji uzmanına kusur atfedilemeyeceği belirtilmiş. Yerel mahkeme tarafından söz konusu İstanbul Adli Tıp Kurumu 3. Intisas Kurulu'nun raporu denetlenebilir mahiyette bulunmakla hükme esas alınarak, davalıların davacının hastalığının teşhisinde ve tedavi aşamasında bir kusurlarının olmadığı kanaatine varılarak davanın reddine karar verilmiştir. ${ }^{[7]}$

Yargıtay Onüçüncü Hukuk Dairesi kararın dayandığı İstanbul Adli Tıp Kurumu 3. İhtisas Kurulu Başkanlığı'nın 09.04.2012 tarihli raporu, davalıların iddia edilen olayda kusurlarının bulunup bulunmadığını tam olarak ortaya koymadığını belirterek mahkemece, üniversitelerden seçilecek bilirkişiler marifetiyle davalıların, davacının rahatsızı̆̆ını teşhiste kusurlarının bulunup bulunmadığı ve kusurları varsa bundan davacının bir zararının doğup doğmadığının anlaşııması için bilirkişi incelemesi yaptırılarak hasıl olacak sonuca göre karar verilmesi gerektiğini belirtmiş ve yerel mahkemenin radyoloji uzmanı ile ortopedi ve travmatoloji uzmanı lehine verdiği kararı bozmuştur. ${ }^{[7]}$

Yorum: Somut davada hekimlerin dikkat ve özen yükümlülüğünden bahsetmek yerinde olacaktır. Hekimler hastalarının gerek tanısında gerekse tedavisinde azami özeni göstermek durumundadır. Bu konu Hasta Hakları Yönetmeliği'nde de belirtilmektedir. ${ }^{[8]}$

Hasta Hakları Yönetmeliği Madde 14'te de belirtildiği gibi, "Personel, hastanın durumunun gerektirdiği tıbbi özeni gösterir. Hastanın hayatını kurtarmak veya sağlığını korumak mümkün olmadığı takdirde dahi, ıstırabını azaltmaya veya dindirmeye çalışmak zorunludur. ${ }^{\text {[8] Hekimden }}$ beklenen kendi branşında ortalama bir hekimin göstermesi gereken özendir.

Burada, üniversite hastanesi tarafından yapılacak bilirkişi incelemesinde söz konusu ilk MR görüntüsünün ortalama bir ortopedi ve travmatoloji uzmanı tarafından tümöral bir lezyon olarak tanınıp tanınamayacağı üzerinde yoğunlaşacaktır. Manyetik rezonans görüntüsünün bariz bir şekilde tümöral lezyonu düşündürmesi hâlinde hem ortopedi ve travmatoloji uzmanına hem de radyoloji uzmanına kusur verilebilecek ve dava ilgili hekimlerin aleyhine sonuçlanabilecektir. 


\section{ÖRNEK OLGU 5}

Örnek olgu, sağlık sigortasından kaynaklanan bir dava. ilgili dava, özel sağlık sigortasından kaynaklanan uyuşmazlıkta hasta tarafından 22.04.2008 tarihinde sağlık sigortası yaptırılmış ve sağlık sigortasının başvuru formunda bulunan beyanların sigortalı tarafından eksik doldurulduğu iddiası üzerine ortaya çıkan uyuşmazlığı konu almaktadır. Davacı özel sağlık sigortasının vekili iddiasında sağlık sigortası yaptıran hastanın sigorta sözleşmesi kurulurken herhangi bir rahatsızlığının bulunup bulunmadığına ilişkin sorulara "hayır" cevabı verdiğini, davalının ameliyatı edildiği sol omuz rahatsızlığının poliçe başlangıç tarihinden önce var olduğu ve bu rahatsızlıkların kapsam dışı olduğu gerekçesi ile sigorta şirketine iade edilmesi gerektiğini belirtmiş. Davalı hasta omzundaki sıkışma (impingement) rahatsızlığının poliçe tarihinden önce olmadığını belirterek davanın reddini talep etmiştir. Yerel mahkeme davalı olan hastanın poliçe tarihinden önce geçirdiği rahatsızlıkların tedavilerinin başvuru formuna konulmadığını, davalının bu konuda yükümlülüğünü yerine getirmediğini belirterek sigorta şirketinin hastaneye yaptıkları ödemelerin hastadan tahsiline karar vermiş, davalı vekiller tarafından karar temyiz edilmiş. Yargıtay Onbirinci Hukuk Dairesi yaptığı inceleme sonucunda yerel mahkemenin kararını onamıştır. ${ }^{[9]}$

Yorum: Özel sağlık sigortası yapılacağı zaman başvurucular kendileriyle ilgili rahatsızıkları tam olarak sigorta şirketine bildirme yükümlülüğündedirler. Sigorta şirketi bildirilen rahatsızlıkları göz önünde bulundurarak poliçe oluşturmaktadır. Hastaların bildiriminde eksiklik olması durumunda somut davada da görüldüğü gibi sigorta şirketi ödenen sağlık bedelini sigortalıdan tahsil edebilmektedir.

\section{KAYNAKLAR}

1. Cerrahi Müdahale Birimlerinde Uygulanacak Cerrahi Müdahale Listesi Hakkında Genelge (2009/42). T.C. Sağlık Bakanlığı Tedavi Hizmetleri Genel Müdürlüğü, 2009/42 sayılı Genelge, Tarihi: 06.07.2009. Erişim adresi: www.saglik.gov.tr (Erişim tarihi: 18.01.2022). Crossref

2. T.C. Danıştay Onbeşinci Hukuk Dairesi, Esas: 2018/1721, Karar: 2018/7403, Tarih: 08.11.2018. Erişim adresi: www.danistay. gov.tr (Erişim tarihi: 15.01.2022).

3. T.C. Yargıtay Onüçüncü Hukuk Dairesi, Esas: 2016/296, Karar: 2018/8383, Tarih: 26.09.2018. Erişim adresi: www.yargitay.gov. tr (Erişim tarihi: 15.01.2022).

4. Ayakta Teşhis ve Tedavi Yapılan Özel Sağlık Kuruluşları Hakkında Yönetmelikte Değişiklik Yapılmasına DairYönetmelik. Resmi Gazete: Tarihi, 10.03.2010; Sayısı, 27517. Erişim adresi: https://resmigazete.gov.tr/eskiler/2010/03/20100310-3.htm (Erişim tarihi 15.01.2022).

5. 2009/42 sayılı Genelgenin yürürlükten kaldırıldığına dair 25.03.2010 tarih ve 12622 sayılı Makam Onayı. Erişim adresi: https://www.saglik.gov.tr/TR,10998/cerrahi-mudahale-birimlerinde-uygulanacak-cerrahi-mudahale-listesi-hakkinda-genelge200942.html (Erişim tarihi: 15.01.2022).

6. T.C. Yargıtay Üçüncü Hukuk Dairesi, Esas: 2020/7914, Karar: 2021/543, Tarih: 27.01.2021. Erişim adresi: www.yargitay.gov. $\operatorname{tr}$ (Erişim tarihi: 15.01.2022).

7. T.C. Yargıtay Onüçüncü Hukuk Dairesi, Esas: 2013/6731, Karar: 2013/17451, Tarih: 25.06.2013. Erişim adresi: www.yargitay. gov.tr (Erişim tarihi: 15.01.2022).

8. Hasta Hakları Yönetmeliği. Resmi Gazete: Tarihi, 01.08.1998; Sayısı, 23420. Erişim adresi: www.mevzuat.gov.tr (Erişim tarihi: 15.01.2022).

9. T.C. Yargıtay Onbirinci Hukuk Dairesi, Esas: 2012/2741, Karar: 2013/3459, Tarih: 26.02.2013. Erişim adresi: www.yargitay.gov. tr (Erişim tarihi: 15.01.2022). 